\title{
In-vitro Evaluation of Some Selected Fungicides against Pestalotio psis clavispora and Pseudocochliobolus eragrostidis Isolated from Vitellaria paradoxaSeedlings.
}

\author{
O.D. ${ }^{1}$ Esiegbuya*, E.A. ${ }^{1}$ Oruade-Dimaro, E.E. ${ }^{1}$ Odigie, F.I. ${ }^{2}$ Okungbowa, O. ${ }^{1} \mathrm{Igb}$ \\ inedion, and A. ${ }^{1}$ Ojieabu. \\ ${ }^{1}$ Plant Pathology Division, Nigerian Institute for Oil Palm Research (NIFOR) P.M. B1030, Benin City. \\ ${ }^{2}$ Department of Plant Biology and Biotechnology, University of Benin, P.M.B 1154, Benin City.
}

\begin{abstract}
Preliminary investigation into the nursery diseases of Vitellaria paradoxa in the Nigerian Institute fo $r$ Oil Palm Research substation, Bida, Niger state, revealed mainly the presence of leaf pustules and leaf blight disease. Symptoms of the leaf pustules disease results in a total defoliation of the leaves of the plant while that of the leaf blight is characterized by fire burnt edges around most of the leaves in a single seedlings or shrub. Mic roorganisms isolated from the infected leaf samples using the direct plating techniques on potato dextrose agar include Pestalotiopsis clavispora and Botryodiplodia (Lasiodiplodia spp) from the leaf pustules while P. clavisp ora and Pseudocochliobolus eragrostidis were isolated from the leaf blight. The result of the effect of the fungici des captan, benlate dithane M-45and difolatan at 500 and $250 \mathrm{ppm}$ on the in-vitro mycelia growth of P. clavispo $\mathrm{ra}$ and $P$. eragrostidis for a test period of nine days shows benlate at 500ppm to completely inhibit the mycelia $g$ rowth of $P$. clavispora and P. eragrostidis. The fungicide dithane did not completely inhibit the pathogens at sa me concentration of 500 and $250 \mathrm{ppm}$. The mode of action of the fungicide benlate on P. clavisopra and P. eragr ostidis was fungicidal. It's therefore recommended that the fungicide benlate be used for field trials.
\end{abstract}

Key words: Blight, Pustules Pestalotiopsis clavispora, Pseudocochliobolus eragrostidis, Vitellaria paradoxa

\section{Introduction}

The Shea butter tree (Vitellaria paradoxa C. F. Gaertn.) is a tree of economic importance as it contributes to red uction of rural poverty, hunger and disease and enhancing environmental sustainability. The fruit pulp, which ha s excellent nutritional content (Ugese et al., 2008) is widely consumed among indigenous peoples of Africa (Ma ranzet al.,2004) while among some ethnic groups, the flowers are made into fritters (ICRAF, 2000).Locally, the oil is used as a cooking fat while in Europe and Japan; it is used in chocolate manufacture (Umali and Nikiema, 2002).Caterpillars of Cirinabutyrospermi, associated with the species are eaten by some ethnic groups in Nigeri a such as the Yoruba, Nupe and Tiv (Ande, 2004; Ugese et al., 2005). Shea butter is also used in production of c osmetics (Boffa et al., 1996). The increasing popularity of the butter in cosmetics the world over is attributed to its skin protecting and rejuvenating properties (FAO, 2006). The tree confers stability on the land resource there by curtailing degradation (Boffa et al., 1996). This is achieved partly through improvement of soil structure by t he slow decomposing leaf litter. Trade in Shea tree products has been reported to improve the incomes and livin $\mathrm{g}$ standards of rural farm families and the economies of exporting countries (Popoola and Tee 2001).

The tree provides many different uses. Shea bark is used for medicine to cure ailments in skin treatment in child ren- especially newborns and treat minor scratches and cuts, the leaves are eaten as a vegetable in Yewa, North Central Nigeria, and Benue (George, 2011, Abidemi, 2009). They also reported that the extract from the leaves has been used to relieve headaches and as an eye bath; the nutshell has a built- in mosquito repellant; and the but ter which has been a central element of this report. Butter made from the Shea nut is used for skin moisturizing c reams and lotions, cooking, soap, and in manufacturing chocolate.

The objective of this study was to assess the incidence of the leaf spot diseases of $V$. paradoxa, identify the caus al organisms and proffer possible control measures using fungicides application.

\section{Material And Methods}

The survey report was conducted in the Nigerian Institute for Oil Palm Research Substation, Bida and Dzujagi c ommunity of Niger State, Nigeria.

Isolation of pathogens

Seedlings of $V$. paradoxa were inspected for various forms of disease symptoms of seedling diseases. Portion of tissue segments of the advancing margin of lesions were excised, surface sterilized by washing samples with sod ium hypochlorite solution and then rinsed about three times in sterile distilled water, blotted dry with sterile tiss ue paper, and plated on potato dextrose agar. The cultures were incubated under room temperature. 


\section{Identification of fungal isolates}

Molecular identification of the isolated pathogens was carried out by the Commonwealth Mycological Institute ( $\mathrm{UK})$.

\section{Fungicidal trials}

In-vitro experiments were carried out to find effective fungicides against the isolated pathogens. Four fungicides namely, Benlate Dithane M-45, Captan, and Difolatan were evaluated at 500 and 250ppm concentrations using the food poison technique. The desired concentrations of the fungicides were obtained by adding appropriate am ount of stock solution of individual fungicide in potato dextrose agar (PDA) medium in conical flask. Amended PDA medium was poured separately into Petri dishes and replicated five times for each treatment. PDA medium without fungicide served as control.

Each plates were inoculated with the mycelial disc of each pathogens $(5 \mathrm{~mm})$ taken from the periphery of 7 day old culture grown on PDA. The inoculated plates were incubated at $28 \pm 1^{\circ} \mathrm{C}$ till the fungus growth covered the pl ate in case of control. The average growth was determined for each isolates at day 3, day 6 and day 9.

\section{Determination of mycelial radial growth}

The centre of each of five replicates PDA plates was inoculated with a $0.5 \mathrm{~cm}$ diameter mycelial disc c ut from the periphery of a 7 day-old culture of each isolates and was incubated at room temperature for 9 days. At 3 days interval, the radial growth of mycelium was measured along the intersecting lines and the mean of the two measurements was recorded for each of three replicates. By subtracting $0.5 \mathrm{~cm}$ initial diameter of inoculum $\mathrm{f}$ rom the mean, the total growth of mycelium was thus determined.

\section{Determination of the fungistatic and funigicidal activity of the fungicides Growth medium}

Modified Czapek dox broth (MCDB) was used as the basal medium for culturing the fungi. The composition of the medium consisted of glucose, 30.0; Yeast extract, $1.0 ; \mathrm{NaNo}_{3}, 2.0 ; \mathrm{KH}_{2} \mathrm{PO}_{4}, 1.0 ; \mathrm{MgSO}_{3} 0.5 ; \mathrm{KCL}, 0.5$ and $\mathrm{FeSO}_{4} 0.01$ ( $\mathrm{g} / \mathrm{l}$ distilled water).The medium was dispensed into a $250 \mathrm{mls}$ conical flask and then sterilized in an autoclaved at $121^{\circ} \mathrm{c}$ for 15 minutes and then evaluated at $250 \mathrm{ppm}$ and $500 \mathrm{ppm}$ with the respective fungicides be nlate, captan difolatan and dithane M45. MCBD medium without fungicides serve as the control.

\section{Inoculation and incubation procedure}

The fungi species was cultured on PDA at $28 \pm 2^{\circ} \mathrm{c}$ for 7 days. A cork borer of $0.5 \mathrm{~cm}$ diameter was used to cut a mycelial disc from the periphery of the 7 day old isolates of P. clavispora and P. eragrostidis then inoc ulated into conical flask containing the MCDB medium. The conical flasks were then incubated for 3, 6 and 9 da ys.The cultures were placed in a rotary shaker to break up the mycelia mat. All experiments were conducted wit $\mathrm{h}$ five replicates

\section{Fungistatic and funigicidal assay procedure}

At the end of each incubation period, the MCDB medium were observed for mycelia growth by harvest ing the inoculated mycelia disc, inoculated on PDA without any fungicides before incubating under room tempe rature.

\section{Leaf pustules disease}

\section{Results}

The study found that all stages of infection of the leaf pustules spot to occur both at the nursery and young field of the plant. The sequence of infection and lesion development were different in all categories of the disease. Inf ections of the leaf pustules in the nursery was observed to have started as small pinhead points from which the le sions enlarged and thus forming a black pustules as shown on plate ii above. The acute stage of the diseases resu lts in a total defoliation of the leaves of the plant (plate iii above). The distribution of the lesions on the leaves di $\mathrm{d}$ not follow any regular pattern. However, lesions traversed all ribs on the lamina, except the midrib. These sy mptoms gradually progress and leads to the death of the plant.

The resulting colonies were white with a regular margin and rough edges. Identifications were undertaken by co mparing the sequence obtained from the sample with those available from the European Molecular Biology Lab oratory (EMBL) database via the European Bioinformatics Institute (EBI). Where matches of 99-100\% identity were obtained, identification was provided to species level or where appropriate to species aggregate, provided $t$ hat matches included a sequence derived from type or other validated culture and when there was a clear sequen ce distinction between taxa. The sequence from this sample showed $100 \%$ identity to ITS sequences reported fro $\mathrm{m}$ various species of Pestalotiopsis including P. clavispora and P. mangiferae with IMI No 502905. 


\section{Leaf blight}

The leaf blight disease is characterized by fire burnt edges around most of the leaves in a single seedlings or shr ub. Acute stage can result in a complete death of the branch showing the symptoms or the seedlings (shrubs stag e)

The ITS sequence obtained from this sample showed top matches at $>99 \%$ identity to ITS sequences from strain s of Curvularia clavata, Curvularia eragrostidis with IMI No 502907and its teleomorphic state Pseudochliobol us eragrostidis (syn. Cochliobolus eragrostidis) and to members of the genus Curvularia which have not been $\mathrm{f}$ ully named to species level. Top matches include $99.8 \%$ identity to a sequence from $P$. eragrostidis (under its sy nonym Cochliobolus eragrostidis). From the morphological examination, conidia were observed to be in the ran ge 20-24 x 11-14 $\mu \mathrm{m}$, broadest in the centre, three-septate with a markedly thickened second septum.

\section{Efficacy of in-vitro fungicidal trial}

The results of the effect of the fungicides benlate, captan, difolatan and dithane M45 at 500 and 250ppm on the $i$ $n$-vitro mycelia growth of $P$. clavispora, for a test period of nine days shows captan at 500 and $250 \mathrm{ppm}$, benlate at $500 \mathrm{ppm}$ and difolatan at $500 \mathrm{ppm}$ to completely inhibit the in-vitro mycelia growth of $P$. clavispora as shown in figure i below. The fungicides dithane did not completely inhibit the same pathogen at the same concentration of 500 and 250ppm. However, signs of growth inhibition were observed by the fungicide dithane M45 for the $\mathrm{p}$ athogens $P$. clavispora when compared to the control during the test period as shown in figure i below.

The results of the effect of the fungicides benlate, captan, difolatan and dithane M45 at 500 and 250ppm on the $i$ nvitro mycelia growth of $P$. eragrostidis, for a test period of nine days shows benlate at 500ppm to completely i nhibit the in-vitro mycelia growth of $P$. eragrostidis as shown in figure ii below. The fungicides captan, difolata $\mathrm{n}$ and dithaneat 500 and $250 \mathrm{ppm}$ did not completely inhibit the pathogen. However, signs of growth inhibition w ere observed by the fungicides on the pathogen P. eragrostidis when compared to the control during the test peri od as shown in figure ii below.

\section{Discussion}

Pestalotia clavisopora and Botryodiplodia (Lasiodiplodia spp) were isolated as microorganisms associ ated with the leaf pustules. This report was also in agreement with the work of Akrofi and Amoah, (2009), who also isolated Pestalotia and Botryodiplodia (Lasiodiplodia spp) from the leaf spot disease of V. paradoxa in Gha na.

The $P$. clavispora isolated from the $V$. paradoxa seedlings in this study were however morphologically similar to that isolated from blueberry in China which was described by Luan et al., (2008) as having a black an d globular acervuli with a diameter of 100 to $200 \mu \mathrm{m}$ long. The base of each was also described to have a swolle $\mathrm{n}$ conidiophores and globose with phialides growing from the apical base. This characteristic morphological feat ures were however observed in the $V$. paradoxa isolate when the $\mathrm{pH}$ of the growth medium (PDA) was slightly akaline.

Pestalotoiopsis Steyaert is an appendage-bearing conidial anamorphic form (coelomycetes) in the famil y Amphisphaeriaceae (Kang et al. 1999), and molecular studies have shown that Pestalotiopsis is monophyletic (Jeewon et al. 2004). Species of Pestalotiopsis are common in tropical and temperate ecosystems (Bate-Smith a nd Metcalfe 1957) and may cause plant disease (Das et al. 2010), are often isolated as endophytes (Watanabe et al., 2010), or occur as saprobes (Liu et al. 2008). The genus has received much attention from the scientific com munity. However, this is not because of its pathogenic nature (Yasuda et al. 2003), but rather because its species have been shown to produce many important secondary metabolites (Xu et al. 2010).

Pseudocochliobolus eragrostidis belongs to the phylum Ascomycota and family Pleosporaceae, and is described as the teleomorph of Cochliobolus eragrostidis (from rice and Eragrostis tef) Tsuda and Ueyama, (1985). C. $e$ ragrostidis has also been reported to cause brown spot disease of asparagus (Salleh et al., 1996), leaf tip blight o f spider lilly causing straw yellow coloured leaf spot which later form necrotic blight, with dark yellow halo inte rfacing diseased. The description of brown leaf spot disease caused by $P$. eragrostidis in $V$. paradoxa seedlings $\mathrm{r}$ ecorded in this study was quite similar to those of the tip leaf blight of spider lilly.

This is the first report of $P$. eragrostidis causing leaf blight disease in $V$. paradoxa seedlings.

The in-vitro control of $P$. clavisopra and $P$. eragrostidis using chemical based fungicides showed captan at 500a nd 250ppm, benlate at 500ppm and difolatan at 500ppmto significantly reduce the mycelia growth of the fungi $P$ .clavisopra from the very first day of the experiment; showing $100 \%$ level of mycelia inhibition by these chemi cals and $0 \%$ level of tolerance by the organism. While the fungicides dithane at 500 and $250 \mathrm{ppm}$ did not record any significant mycelia inhibition. Captan, difolatan and dithane M-45, were not significantly effective in the re duction of the pathogenic activities of P. eragrostidis compared to the control experimental set up; as $100 \%$ leve 1 of tolerance to the chemical based fungicides was recorded on potato dextrose agar treated with these fungicide S. 
There was an increased inhibition of the mycelia growth of the pathogens $P$.clavisopra and $P$. eragrostidis with increase concentration of the active ingredients. Benlate (Benomyl) was the most effective and potent while cap tan and dithame M45 performed poorly. Pandey (1988) also showed that captan performed poorly, but it had an adverse effect on the phylloplane of guava. The effectiveness of captan, dithane M45, and difolatan may be impr oved with further increase in their concentration.

Oruade-Dimaro, (2010), reported that the ability of the fungal discs to resume growth when taken from inhibitor y level to PDA without fungicides showed that the fungicides were fungistatic. In this study, P. eragrostidis and $P$. clavispora did not resume growth when taken away from PDA containing benlate, showed that benlate had a fungicidal effect on $P$. eragrostidis and P. clavispora.

The fungicides benlate (Benomyl) is a systemic benzimidazole fungicide that is selectively toxic to microorgani sms and invertebrates. It functions by interfering with meiosis and intracellular transportation.It is used against a wide range of fungal diseases of fields' crops, fruits, nuts ornamentals, mushroom and tuff. Formulations includ e wettable powder, dry flowable powder and dispersible granules (Wierzbicka, 1987).

The ability of the fungicides benlate to completely inhibit the growth of P. clavispora and P. eragrostidis maybe attributed to it functions of interfering with meiosis and intracellular transportation.

In the control of the leaf pustules and leaf blight diseases of $V$. paradoxa, it is recommended that the fungicides benlate be used for field trials.

However due to the high risk of fungicides to humans, animals, environmental and the increasing rate at which $\mathrm{p}$ athogens develop resistance against fungicides, it therefore necessary to developed a more integrated approach which needs to be used simultaneously so as to reduce economic and environmental problems.

\section{Acknowledgement}

The authors'are indeed grateful to the commonwealth mycological institute (CABI) for the molecular identificat ion of the pathogens and also to the Management of the Nigerian Institute for Oil Palm Research for providing $\mathrm{f}$ unds for this research work.

\section{References}

[1] Abidemi TA, Adebayo OJ, Idowu O. and Agbotoba (2009) Nutrient content and anti-nutritional factors in shea butter (Butryospermum parkii) leaves Afr J Biotech. 8 (21), 5888-5890

[2] AkrofiAY and AmoahFM( 2009) Pestalotia sp. causes leaf spot of Vitellaria paradoxa in Ghana . Afri J Agric Res. 4 (4), $330-333$

[3] Ande A. T(2004)Thepupal habits of Cirinaforda, a leading food insect in Kwara state, Nigeria. J Sust Trop Agric Res 9: 97-100.

[4] Bate-Smith EC, Metcalfe CR. (1957) Leucanthocyanins The nature and systematic distribution of tannin in dicotyledonous plants. $J$ Linn Soc Bot 55:669-705

[5] Boffa, JM, Yameogo, G,Nikiema, P. and Taonda JB: (1996). What future for the Shea tree? Agroforestry Today 8: 5-9.

[6] Das R, Chutia M, Das K, Jha DK(2010) Factors affecting sporulation of Pestalotiopsis disseminata causing grey blight disease of Persea bombycina Kost., the primary food plant of muga silkworm. Crop Prot 29:963-968

[7] FAO (2006) Shea butter becoming popular in Europe. Non-wood News No. 13, April, 2006. pp92.

[8] George C, Shams AN. and Dunkel, FV. (2011) Lessons Learned in an International Service-Learning Collaborative: Shea Butter Case Study North Amer Col and Teachers of Agric J. 71-77

[9] ICRAF:( 2000) International Centre for Research in Agroforestry. Agro forestry Database 2000.in Ghana, Afr J Agric Res4 (4):330333.

[10] Jeewon R, Liew ECY and Hyde KD.( 2004) Phylogenetic evaluation of species nomenclature of Pestalotiopsis in relation to host association. Fungal Divers 17:39-55.

[11] Kang JC, Hyde KD, Kong RYC.( 1999) Studies on the Amphisphaeriales. The Amphisphaeriaceae (sensu stricto). Myco Res 103:5364

[12] Luan Y.S., Shang, Z.T and Su Q . (2008)First report of Pestalotiopsis sp. causing leaf spot of Blueberry in China. Plant Dis. 92(1):171.

[13] Liu L, Liu S, Jiang L, Chen X, Guo L, Che Y (2008) Chloropupukeananin, the first chlorinated pupukeanane derivative, and its precursors from Pestalotiopsis fici. Org Lett 10:1397-1400

[14] Maranz S, Kpikpi W, Wiesman Z, Saint Saveur A. and Chapagain B (2004). Nutritional values and indigenous preferences for shea fruits (Vitellaria paradoxa C. F. Gaertn. F.) in African Agroforetry parklands. Econ Bot 58: 588-600.

[15] Oruade-Dimaro, E.A. (2010) Effects of some physiochemical factors on mycelia growth and conidial germination of Glomerella cingulata (Stonem) Spauld\&Shrenk. Nig J Palms and Oil seeds 17: 67-77

[16] Pandey, R.R (1988) A revision of the genus Raphia Beauv, Palmae. J. Nig Inst for Oil Res 145-189

[17] Popoola L. and Tee NT. (2001). Potentials of Vitellaria paradoxa Gaertn F.in Agroforestry systems in Benue State. Nig J Eco 16: 2024.

[18] Salleh, B., Safinath, A., Julia, L. and Teo. CH (1996). Brown spot caused by Culvularia spp., a new disease of asparagus. BIOTROPHA, 9: 26-37

[19] Tsuda and Ueyama, (1985), Two new Pseudocochliobolus and a new species of Culvularia Trans Myco Soc Japan 26(3):321-330

[20] Ugese FD, Ojo AA. and Bello LL. (2005). Effect of pre sowing treatment and nut orientation on emergence and seedling growth of seeds of shea butter tree (Vitellaria paradoxa) Nig J Bot 18: 294-304.

[21] Ugese, FD, Baiyeri, KP and Mbah, BN (2008): Nutritional composition of shea (Vitellaria paradoxa) fruit pulp across its major distribution zones in Nigeria. Fruits 63: 163-169

[22] Umali, B.E. and Nikiema A(2002)Vitellaria paradoxa C. F. Gaertn. Record from Protabase. Oyen, L P A and Lemmens, R H M J (Editors). PROTA, Wageningen, the Netherlands.

[23] Watanabe K, Motohashi K, Ono Y (2010) Description of Pestalotiopsis pallidotheae: a new species from Japan. Mycosci 51:182-188

[24] Wierzbicka M. (1987) Lead translocation and localization in Allium cepa roots. Can J Bot 65: 4008-4026. 
[25] Xu J, Ebada SS, Proksch, P. (2010) Pestalotiopsis a highly creative genus: chemistry and bioactivity of secondary metabolites. Fungal Diver 44(1):15-31

[26] Yasuda F, Kobayashi T, Watanabe H, Izawa H. (2003) Addition of Pestalotiopsis spp. to leaf spot pathogens of Japanese persimmon. J GenPlant Patholo 69:29-32

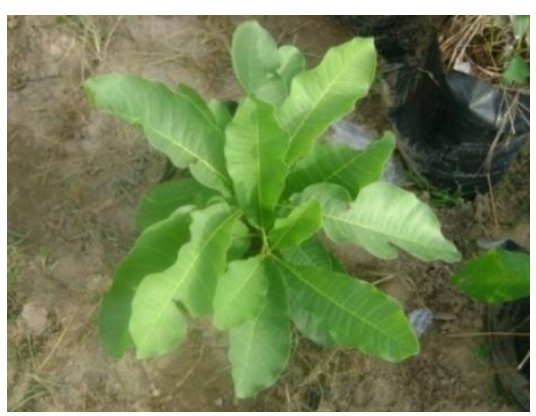

Plate i: Healthy Shea seedlings

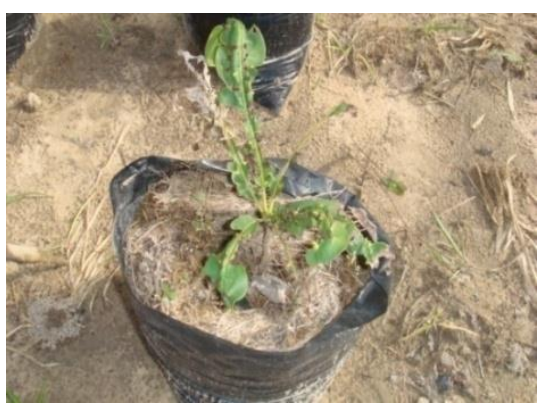

Plate iii: Chronic stage of the leafspot disease with pustules erature for 7 days

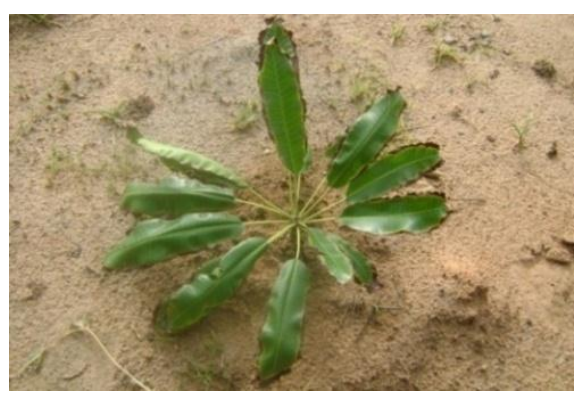

Plate v: Leaf blight disease of Shea seedlings ays

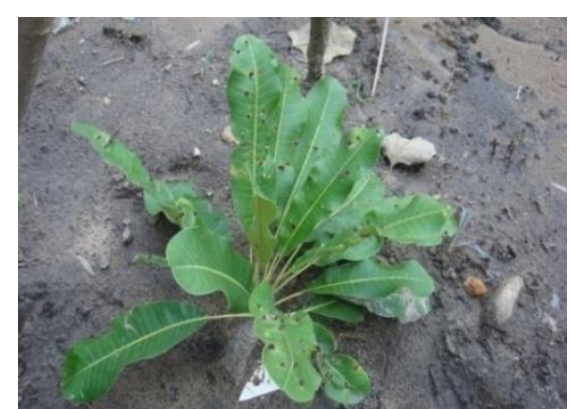

Plate ii: Acute stage of the leafspot disease with pustules

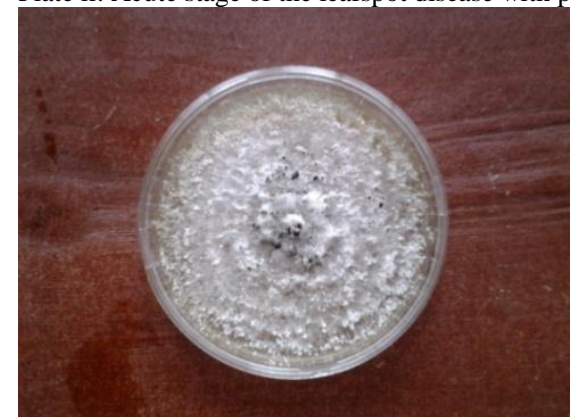

Plate iv: Culture plate of P. clavisopragrown on PDA under room temp

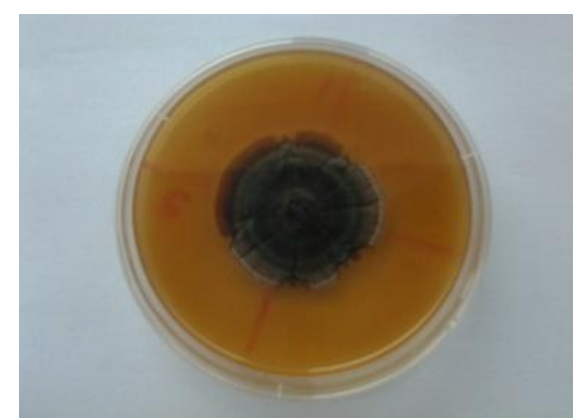

Plate vi: Culture of $P$. eragrostidis grown on PDA under room temperature for $7 \mathrm{~d}$

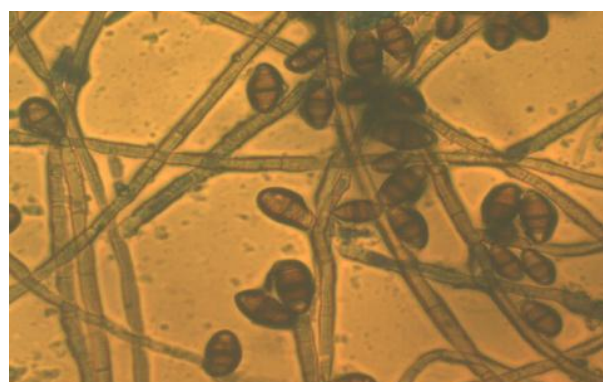

Plate vii: Photomicrograph of P. eragrostidis grown on PDA under room temperature for 7 days

Table i: Morphological description of the microorganisms associated with $V$. paradoxaseedlings

\begin{tabular}{lcc}
\hline Disease type & Organisms suspected & Morphological description \\
\hline Leaf pustules & Pestalotiopsisclavispora & White mycelia growth \\
& Botryodiplodia(Lasiodiplodiasp) & Black fluffy mycelia growthLe \\
af blight & Pestalotiopsis clavispora & White mycelia growth \\
& Pseudocochlioboluseragrostidis & Black mycelia growth \\
\hline
\end{tabular}




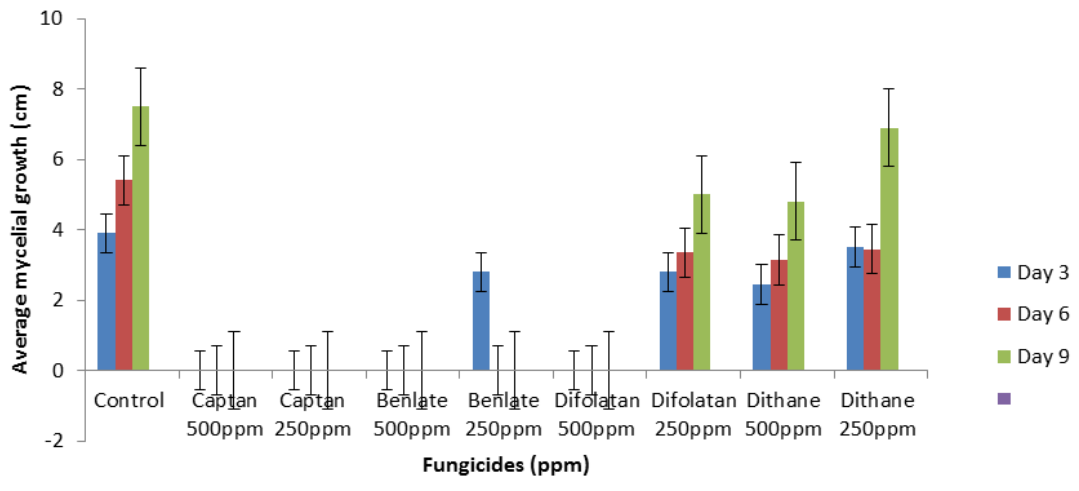

Error bars represent the S.E for the five replicates

Figure i: Effect of Captan, Dithane, Difolatan, and Benlate fungicides at 500 and 250ppm on the in-vitro mycelia growth of $P$. clavisp ora grown on PDA under room temperature for 9 days.

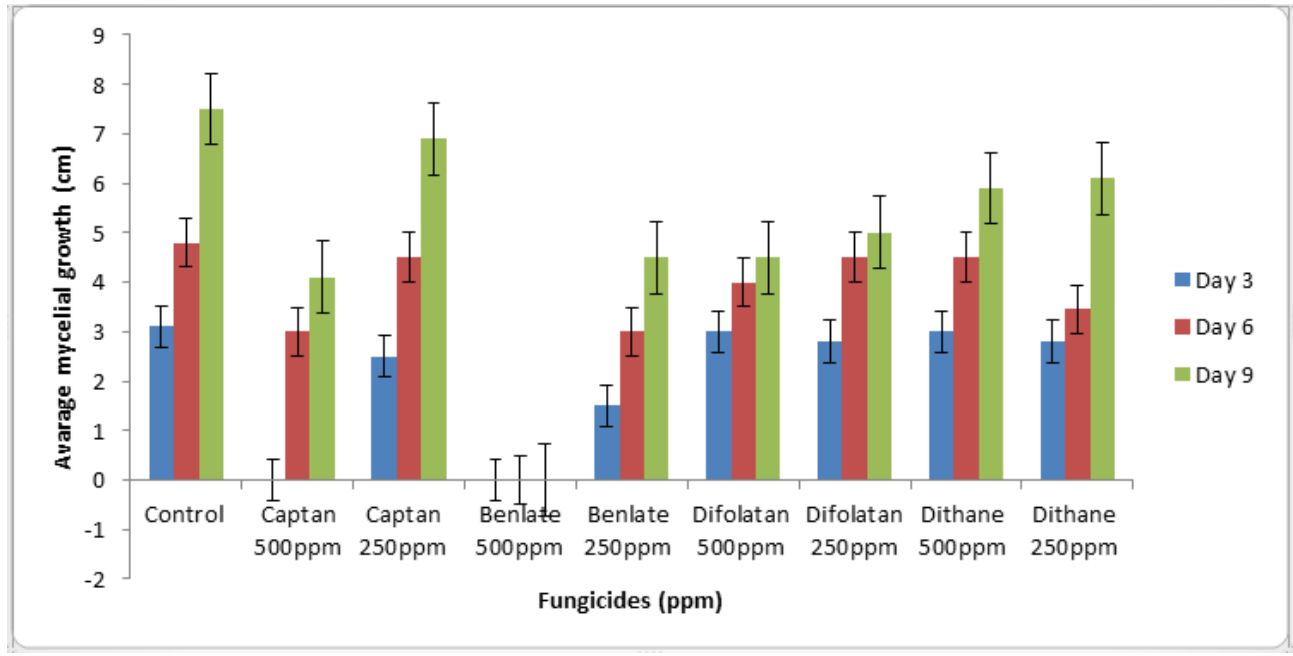

Error bars represent the S.E for the five replicates

Figure ii: Effect of Captan, Dithane, Difolatan, and Benlate fungicides at 250ppm on the in-vitro myelial growth of P. eragrostidis $\mathrm{g}$ rown on PDA under room temperature for 9 days. 